\title{
Influence of structural features on Portuguese toddler child care quality
}

\author{
Manuela Pessanha $^{\mathrm{a}, *}$, Cecília Aguiar ${ }^{\mathrm{b}}$, Joaquim Bairrão ${ }^{\mathrm{b}}$ \\ ${ }^{a}$ College of Education, Porto Polytechnic Institute, Portugal \\ ${ }^{\mathrm{b}}$ University of Porto, Department of Psychology and Educational Sciences, Portugal
}

Received 2 November 2006; received in revised form 19 February 2007; accepted 24 February 2007

\begin{abstract}
Whereas child care quality has been extensively studied in the U.S., there is much less information about the quality of child care in other countries. With one of the highest maternal employment rates in Europe, it is important to examine child care in Portugal. Thirty toddler classrooms in child care centers were observed. The purpose of this study was to determine whether structural features account for overall toddler child care quality. Results showed younger and better-paid teachers provided better toddler child care quality. Space available per child was not a statistically significant predictor of toddler child care quality. Overall quality results suggest some issues to be addressed by early education policy makers and indicate the need to promote quality in Portuguese toddler child care programs. (C) 2007 Elsevier Inc. All rights reserved.
\end{abstract}

Keywords: Child care; Quality; Toddler; Structural features

In Portugal, early childhood education services for children between 4 months and 3 years of age include: infant-toddler child care or crèches (public and private, and in the second case, for-profit and nonprofit), miniinfant-toddler child care or mini-crèches (smaller public programs caring for only 12-15 children), official nannies (self-employed home day care providers who care up to four children and receive a salary from the Ministry of Labour and Welfare) and family crèches or family day care (groups of 12-20 nannies, in the same geographical area, who are technically and financially supported by Social Security Regional Centres). These contexts are all dependent from the Ministry of Labour and Welfare and are set up either by the Ministry itself or by other entities such as private individuals, cooperatives, private institutions of social solidarity (private non-profit organizations established for social purposes) or other non-profit institutions (Bairrão, Barbosa, Borges, Cruz, \& Macedo-Pinto, 1990; Vasconcelos, Orey, Homem, \& Cabral, 2002).

Early childhood education services for children from 3 to 6 years of age include: (1) preschool (public or private formal programs serving groups of preschoolers), (2) socio-educational activities (activities directed to children to supplement the educational contexts timetable and keep them safe and occupied until their parents finish work) provided by both the Ministry of Education and the Ministry of Labour and Welfare, (3) community and cultural activities (serving 5-year-old children from highly populated deprived areas), and (4) itinerant child education (services directed to children who live in rural areas where the number of children does not reach the minimum required for setting up a preschool)

\footnotetext{
* Corresponding author at: Escola Superior de Educação, Instituto Politécnico do Porto, Rua Dr. Roberto Frias, 4200-465 Porto, Portugal. Tel.: +351225073488.

E-mail address: pessanha@ese.ipp.pt (M. Pessanha).
} 
(Bairrão et al., 1990; Ministério da Educação, 2000). The public and the private preschool networks together form a national network, dependent from the Ministry of Education, whose aim is to extend preschool education provision to all children of this age group.

Portugal has made notable progress in early childhood education and care policy formulation and implementation (Organization for Economic Co-operation and Development [OECD], 2001). A government Program for the Expansion and Development of the Preschool Education was drafted in 1996. This program intends that the expansion and development of pre-school provision should take place in co-ordination with municipal, private, and social welfare institutions, with central government assuming a guiding and regulatory role (OECD, 2001).

In recent years, substantial efforts have been made to increase the Portuguese coverage rate of early childhood education services. In 1996, the coverage rate for children between 4 months and 3 years of age was 12.65\% (Vasconcelos et al., 2002). Presently, the coverage rate in infant-toddler child care is approximately 19\% (Ministério da Educação, 2002). The coverage of early care and education services for children between 3 and 6 years has grown from 35.5\% (in 1994) to 73.9\% (in 2001) (Ministério da Educação, 2002).

This constant growth is related to the increasing demand for early childhood services outside the family context, because of the considerable increase of working mothers. Portugal has the highest rate of mothers working full time in the European Union: in 2001, $71 \%$ of all mothers were employed and only $11 \%$ of these were working part-time (OECD, 2004). According to the same source, the age of the youngest child has relatively little influence on maternal employment rates in Portugal.

The recognition of the critical importance of educational experiences in the early years has also contributed to the growth of the national infant-toddler child care and preschool network. Considerable evidence suggests that participation in quality childhood education programs has positive effects on the latter school adaptation and success in the United States of America (for summaries, see Lamb, 1998) and in Europe (Bairrão \& Tietze, 1995). Therefore, since a progressively larger number of children spend a considerable part of their day in infant-toddler child care or preschool, it is important to study the quality and effects of these programs on children's development and education.

Over the past decade, researchers have come to recognize the diversity and complexity of child care arrangements and their effects on children (e.g., National Institute on Child Health and Human Development Early Child Care Research Network, 2005). Children grow up in a heterogeneous array of cultural and family circumstances, and may also experience multiple types of nonparental care. Increasing awareness that the quality of care may play a crucial role in determining how children are affected by nonparental care has fostered efforts to understand how care providers behave and how they should be trained to provide growth-promoting care for children (Lamb, 1998). Therefore, high-quality alternative care is crucial.

However, out-of-home, non-familial child care quality is much more difficult to define than one might think. Most of the available literature on early childhood programs suggests that quality can be assessed by identifying selected characteristics of the program, the setting, the equipment, and other features, as seen by the adults in charge of the program. According to Katz (1998), such an approach can be called an assessment of quality from a top-down perspective. Another approach is to take what might be called a bottom-up perspective by attempting to determine how the program is actually experienced by the participating children. A third approach, which could be called an inside-outside perspective, is to assess how the program is experienced by the families it serves. A fourth perspective is one from the inside, which considers how the program is experienced by the staff who work in it. A fifth perspective takes into account how the community and the larger society are served by a program. This can be called the outside perspective on program quality (Katz, 1998).

The top-down perspective on quality typically takes into account measures used to assess structural aspects of the quality of care (physical and social characteristics of settings), including adult-child ratios, level of care provider training and experience, and the adequacy of the physical facilities. However, structural characteristics affect the likelihood of high-quality care, but they do not guarantee it (e.g., Cryer, Tietze, Burchinal, Leal, \& Palacios, 1999; Phillipsen, Burchinal, Howes, \& Cryer, 1997).

Two approaches to the measurement of quality have been pursued: process and structural measures. Observational measures of the settings and of the interactions between care providers and children are often described as process measures. The Assessment Profile for Early Childhood Programs (Abbott-Shim \& Sibley, 1987) and the Child Care Facility Schedule (World Health Organization, 1990) are examples of process measures. However, the process quality standardized measures developed by Thelma Harms, Debby Cryer and Richard Clifford have been the most widely used by international researchers: The Infant-Toddler Environment Rating Scale (ITERS; Harms, Cryer, \& Clifford, 
1990a) and its revised version (ITERS-R; Harms, Cryer, \& Clifford, 2003) and the Early Childhood Environment Rating Scale (ECERS; Harms \& Clifford, 1980) and its revised version (ECERS-R; Harms, Clifford, \& Cryer, 1998).

In addition, many researchers index quality using a number of structural indices because these indices can be more readily observed and legislated. These include measures of teacher training and experience, group size, teacher-child ratio, and crowding. Identification of structural aspects of center child care that are predictive of child care quality has long been a goal of developmentalists, policy makers, and parents. Much of this research has focused on the impact of structural variables like adult-child ratio, group size and teacher education/training on child care process quality (e.g., Blau, 2000; Cryer et al., 1999). However, according to Phillipsen et al. (1997), most studies have not examined the relations between teaching staff characteristics and center characteristics hierarchically to determine their relative impact, especially for infant or toddler care.

In a study conducted by Phillipsen et al. (1997), 228 rooms attended by zero to 24-month-old children and 521 rooms attended by 3-4 year-old children were observed in order to identify structural features associated with the quality of care provided. The results showed that in zero to 24-month-old child classrooms, process quality was higher in classrooms where teachers were more experienced, were better paid, and whose directors were more experienced. In 3-4-year-old child classrooms, quality was higher in those where teachers were more educated, had some experience, and were better paid. These results permitted the authors to conclude that teachers' wage was strongly related to process quality, being of predictive value of that quality.

Howes (1997) found similar results when examining the associations between teachers' education and adult-child ratio in child care settings. Two representative samples were used: 655 classrooms from The Cost, Quality and Outcomes Study and 410 classrooms from The Florida Quality Improvement Study. Classrooms were classified through adult-child ratio and teachers' education. Children and teachers' behaviors were compared based on that classification. Results showed that in both samples teachers' education influenced teaching behaviors, activities, and children outcomes. However, no interactions were found between adult-child ratio and teachers' education.

In a more recent study conducted by Blau (2000), data from The Cost, Quality and Outcomes Study (1995) were used to examine how group size, adult-child ratio, and teacher education affected the quality of care provided to 0-3-year-old children. Results showed that group size had little and a nonsignificative effect on the quality of care provided. The same was found for teachers' education. However, smaller adult-child ratios had a positive effect on classroom quality.

In many European countries, preschool education quality is also a concern. Attempts at assessing, maintaining, and improving the quality of care provided are topics in researchers, educators, and policy makers agendas. This concern had led to different studies, some of them revealing surprising and contradictory results when compared with those obtained in the United States (e.g., Hagekull \& Bohlin, 1995; Tietze, Cryer, Bairrão, Palacios, \& Wetzel, 1996; van Ijzendoorn, Tavecchio, Stams, Verhoeven, \& Reiling, 1998).

Early childhood education and care has experienced a surge of policy attention in the OECD countries over the past decade. Policy makers have recognized that equitable access to quality early childhood education and care can strengthen the foundations of lifelong learning for all children and support the educational and social needs of families. Recognizing that the cross-national information and analysis can contribute to the improvement of policy development, the OECD Education Committee launched, in 1998, a Thematic Review of Early Childhood Education and Care Policy. Twelve countries volunteered to participate in this review: Australia, Belgium, the Czech Republic, Denmark, Finland, Italy, the Netherlands, Norway, Portugal, Sweden, the United Kingdom and the United States of America. The term early childhood education and care (ECEC) includes all arrangements providing care and education for children regardless of setting, funding, opening hours, or program content. According to this review, definitions of quality differ considerably among stakeholder groups and across countries. However, many common elements in definitions of quality exist, especially for provision for children from the age of 3 to 6 . Most countries focus on similar structural aspects of quality (e.g., staff-child ratios, group size, facility conditions, staff training), which tend to be weaker for infant-toddler provision. Major quality concerns that emerged during the review include: lack of coherence and coordination of ECEC policy and provision; the low status and training of staff in the social welfare sector; the lower standards of provision for children under three; and the tendency for children from low-income families to receive inferior services. However, policy for the under three group is closely linked with the nature of available parental leave arrangements and social views about caring. Also in many countries, the education and care of young children is shifting from the private to the public domain, with much attention to the complementary roles of families and ECEC institutions in young children's early development and learning (OECD, 2001). 
In a study conducted in Holland by van Ijzendoorn et al. (1998), 43 child care centers were observed in order to verify if care setting formal features, like group size and adult-child ratio, and teachers' features, such as age, education, and experience were related to the quality of care provided. The authors were able to discriminate between good and moderate quality center care, on the basis of four predictors: age of caregiver (older caregivers provided better quality), professional's education (less educated caregivers provided better quality), years of experience (caregivers with less experience provided better quality), and hours per week at work (caregivers working fewer hours provided better quality care).

Using a composite score of ITERS and ECERS, the authors found that the quality of center care in Holland was good $(M=4.8)$ compared with that of other countries, including the United States. In particular, centers appear to be well equipped and to display a clear program structure. One of the determinants of that quality might be the strict national regulation of some important conditions of child care, such as group size and professional education. On the other hand, formal characteristics of the professional caregivers appeared to be the most powerful predictors of quality of care. Older caregivers provided better quality than younger caregivers. Less experienced and less educated caregivers who spent fewer hours per week at the center were also found to provide higher quality of care.

In the European Child Care and Education Study (ECCE Study Group, 1997a; see Cryer et al., 1999 and Tietze et al., 1996) conducted in four European countries, Germany, Portugal, Spain, and Austria, between 1992 and 1998, results showed that Austrian and German child care centers had better results on ECERS in part because these two countries had more solid infrastructures that support high-quality preschool education. On the other hand, Spain obtained the lowest values on ECERS because of a traditionally more academic approach and due to facilities and equipment that limited play activities.

In Portugal (Bairrão, Leal, Abreu-Lima, \& Morgado, 1997; Bairrão, Leal, \& Gamelas, 1999; Cryer et al., 1999) the study aimed to obtain an overall picture of preschool quality. Process quality of 88 preschool classrooms was assessed through the ECERS and structural features were assessed through questionnaires answered by teachers and center directors. Regarding process quality, results showed that $72 \%$ of Portuguese preschool classrooms were of moderate quality. The authors also found that some structural features were powerful predictors of those ECERS values: room size was the most powerful predictor of global quality (more classroom space was related to higher quality scores), followed by teachers' experience (more experienced teachers provided better quality), center geographical location (higher quality scores were found in the south of Portugal), and amount of time used by teachers to plan activities (more time to plan activities was related to higher quality scores).

More recently, as part of a broader research project developed by the Department of Psychology University of Porto, which looked at the quality of interactions within family and infant-toddler child care settings, and its influence on children's cognitive development, Aguiar, Bairrão, and Barros (2002) analyzed the quality of 30 classrooms in 15 for-profit and nonprofit infant-toddler child care centers and came to different findings. The overall quality of the assessed classrooms, as Harms et al. (1990a) described it, was found to vary between inadequate and minimal.

Developed within the scope of the same project, the aim of the present work was to determine whether structural features, namely classroom and teacher characteristics, can predict the overall quality of the observed classrooms assessed by the ITERS. Building simultaneously on the ECCE study findings on classroom space (see Cryer et al., 1999), on research that identifies space available per child as an environmental feature that influences children's well being (e.g., Legendre, 2003) and on Portuguese regulations on child care space requirements, we were interested in determining the contribution of space available per child to classroom overall process quality. We expected classrooms with higher amounts of space available per child to display higher process quality as assessed by ITERS. Finally, building on the findings reported by van Ijzendoorn et al. (1998) and Phillipsen et al. (1997), we expected older teachers to provide better quality child care on the one hand and better paid teachers to provide better quality child care on the other hand.

\section{Method}

\subsection{Participants}

Thirty toddler child care classrooms from 15 private child care centers in the Metropolitan Area of Porto participated in this study. In the north of the country, Porto is the second largest city in Portugal: its Metropolitan Area has approximately 1,200,000 inhabitants (Instituto Nacional de Estatística, 2003). 
Table 1

Demographic information on teacher participants

\begin{tabular}{lcc}
\hline & $N$ & $\%$ of participants \\
\hline Female & 30 & 100 \\
Caucasian/White & 30 & 100 \\
Highest level of formal education & & 10 \\
9th grade & 3 & 7 \\
Between 9th and 12th grade & 2 & 57 \\
Bachelor's degree (3 years of college education) & 17 & 27 \\
Licenciate degree (4 years of college education) & 8 & 33 \\
Years of child care experience & & 30 \\
$0-5$ & 10 & 13 \\
$6-10$ & 9 & 23 \\
$11-15$ & 4 & 7 \\
\hline 16 & & \\
\hline
\end{tabular}

Of the 15 participating centers, 11 were nonprofit and four were for-profit. Centers were randomly selected from a list provided by regional welfare services (which included a population of 92 nonprofit and 85 for-profit centers that provided services for children under 3 years of age). To be included in the study centers had to include two toddler classrooms: a classroom for 1 year olds and a classroom for 2 year olds.

Once a program had been randomly selected, directors were sent letters and telephoned to ensure that the program met the requirements for inclusion and to provide the requested information about the research project. When the director gave permission for the center to participate in the study, an appointment was made to make the necessary arrangements for data collection. During these meetings, center directors and classroom teachers were given a written summary of the project goals, were given oral information on the data collection procedures and were asked to participate based on this information. Parents of the children attending each classroom were also informed of the research project activities and gave their consent to the inclusion on their children in the classroom during data collection.

Center directors identified the lead adult in each classroom: the trained or untrained teacher responsible for the classroom or, in some cases, the untrained teacher that spent more time with the group of children. Five, 1 year old classrooms were led by untrained teachers (although with the supervision of a trained teacher) and the remaining classrooms were led by trained teachers. These 30 adults will be referred to as lead teachers for the remaining of this work. Of the teachers who participated, all were female. Table 1 provides additional demographic information on the teachers in the study.

Participation rate for the centers that we contacted was 58\%. Of the 43 centers we contacted, 17 were excluded for not meeting the necessary requirements and were not asked to participate (16 of those were for-profit). Of the 26 eligible centers remaining, 11 refused to participate ( 8 of which were for-profit). Except for the type of center (profit status), there is no information available on the centers that refused to participate.

Maximum group size of the individual classrooms ranged from eight to 25 children $(M=15.73)$ and the number of adults in these classrooms ranged from one to five $(M=2.43)$. The child-adult ratio ranged from 4:1 to 18:1 $(M=7: 1)$.

\subsection{Instruments}

The Infant-Toddler Environment Rating Scale-ITERS (Harms et al., 1990a) was used to assess the global quality of the individual classrooms. A Portuguese temporary translation was used (Harms, Cryer, \& Clifford, 1990b). The translation procedure was conducted as follows: two Portuguese versions were made, a first version was conducted by a researcher with a masters degree in Psychology and a certificate of proficiency in English from the British Institute of Oporto and a second version was conducted by a finalist of the undergraduate program in Psychology with extensive knowledge of the English language. The translation used in this study was constructed based on the comparison of these two working versions and on its discussion with a senior scientist working in the field of early childhood education.

The ITERS gives an overall picture of the quality of group care provided for children up to 30 months of age. This scale consists of 35 items, organized under seven categories: Furnishings and display for children, Personal 
care routines, Listening and talking, Learning activities, Interaction, Program structure, and Adult needs. Each item is presented as a 7-point scale, with descriptors for 1 (inadequate), 3 (minimal), 5 (good), and 7 (excellent). High reliability and validity have been reported for the ITERS (Harms et al., 1990a).

Cronbach's alpha was calculated to estimate the internal consistency of ITERS data on this Portuguese sample. Only 33 items were used for this specific analysis: item 31 (Provisions for exceptional children) was excluded because it was applied to only one classroom and item 23 (Sand and water play) was excluded because no variance was found (participating classrooms did not offer sand and water play). Cronbach's alpha coefficient on the overall score was .80.

Structural measures were collected using the Preschool and Daycare Structural Characteristics Questionnaire-Interview with the Classroom Teacher (ECCE Study Group, 1997b).

\subsection{Procedure}

\subsubsection{Training}

Prior to classroom observation, seven observers participated in a training session led by one of the authors of the Portuguese translation of the ITERS. Most observers had previous experience with ITERS. Training included direct instruction on using the scale, video observations, and discussions on the rating system.

\subsubsection{Data collection}

Data collectors remained an average of 4 weeks in each classroom, typically in the morning, in order to collect data on several measures not included in this particular study. ITERS was rated once, in the end of the data collection period, based on the observations of materials, activities, routines, and interactions made during that extended period of time and on the information provided by the lead teacher during the interview necessary to rate the ITERS. Although the authors of the rating scale recommend an observation period of at least $2 \mathrm{~h}$, we decided to include all the information available for each of the participating classrooms. Owing to limited funds, interobserver agreement could not be calculated for the ITERS. However, because data collection on other measures not included in this study required the presence of a second observer $25 \%$ of the time, in most cases, ratings on ITERS items were discussed between the two observers that collected data in each child care center (at the end of the data collection procedure).

\subsubsection{Data analysis}

For descriptive purposes, we examined the correlations between the structural aspects of child care (i.e., space available per child, teacher's age and experience, teachers salary, group size, number of adults, and child-teacher ratio) and global child care quality (i.e., the overall ITERS score). We also examined the means, standard deviations and range of selected process and structural variables. Finally, a hierarchical regression determined if structural classroom and teacher characteristics predicted overall process quality. A hierarchical regression was used in order to determine to what extent each structural characteristic added to the prediction of global quality, after controlling for other structural features. Hierarchical regression was chosen also because the independent variables used in the regression model were different in nature (classroom characteristics, teacher personal characteristics, and teacher working conditions). Owing to the small number of cases, we only included three variables in the model. Effect sizes were computed using Cohen's $f^{2}$ (see Cohen, 1992).

\section{Results}

Descriptive analysis examined the correlations between overall process quality (i.e., the overall ITERS score) and structural variables of conceptual interest (see Table 2). We found moderate statistically significant correlations between overall child care quality and teacher's salary (positive association) and teacher's age (negative association). Small nonsignificant correlations were found between child care quality and the following structural characteristics: space available per child (positive association), teachers' experience and child-teacher ratio (negative associations). No associations were found between child care quality and group size and number of adults in the classroom. Because of the limited number of participating classrooms, and based on a statistical criterion (see Tabachnick \& Fidell, 1996), we decided to use only three structure variables as predictors in further analysis: space available per child (a regulable feature of child care classrooms), teachers' age (strongly associated with teachers' experience but preferred due to its stronger association with overall quality), and teachers' salary per month. Thus, decisions on variable selection 
Table 2

Correlations between process quality and structural variables $(n=30)$

\begin{tabular}{|c|c|c|c|c|c|c|c|c|}
\hline & $\begin{array}{l}\text { Process Quality } \\
\text { (ITERS) }\end{array}$ & $\begin{array}{l}\text { Space available } \\
\text { per child }\left(\mathrm{m}^{2}\right)\end{array}$ & Teachers' age & $\begin{array}{l}\text { Teachers' salary } \\
\text { per month } \\
\text { (EURO) }\end{array}$ & $\begin{array}{l}\text { Maximum } \\
\text { group size }\end{array}$ & $\begin{array}{l}\text { Number of } \\
\text { adults }\end{array}$ & $\begin{array}{l}\text { Teachers' } \\
\text { experience }\end{array}$ & $\begin{array}{l}\text { Child-teacher } \\
\text { ratio }\end{array}$ \\
\hline Process quality (ITERS) & & .25 & $-.40^{*}$ & $.42^{*}$ & .05 & .08 & -.24 & .22 \\
\hline Space available per child $\left(\mathrm{m}^{2}\right)$ & & & .25 & -.13 & -.24 & .13 & .14 & -.29 \\
\hline Teachers' age & & & & .05 & -.08 & -.06 & $.84^{* *}$ & -.18 \\
\hline Teachers' salary per month (EURO) & & & & & .32 & .18 & .19 & .04 \\
\hline Maximum group size & & & & & & $.54^{* *}$ & .02 & .09 \\
\hline Number of adults & & & & & & & .05 & $-.60^{* *}$ \\
\hline Teachers' experience & & & & & & & & -.26 \\
\hline
\end{tabular}

$-.26$ 
Table 3

Means, standard deviations and range for process quality and structural variables $(n=30)$

\begin{tabular}{lrrr}
\hline & \multicolumn{1}{c}{$M$} & \multicolumn{1}{c}{ S.D. } & Range \\
\hline Process quality (ITERS) & 2.60 & .45 & $1.76-3.47$ \\
Space available per child $\left(\mathrm{m}^{2}\right)$ & 2.70 & 1.37 & $.95-6.95$ \\
Teachers' age & 32.93 & 6.70 & $23-47$ \\
Teachers' salary per month (EURO) & 600.99 & 152.30 & $360-837.98$ \\
\hline
\end{tabular}

were based on both theoretical and statistical information (i.e., stronger predictor-outcome correlation coefficients). A variable of conceptual interest such as teacher education was not included in the analysis due to low variability (see Table 1) and violation of normality assumptions. Except for teacher's age and experience, selected structural variables were not strongly associated with other structural features of child care included in our analysis.

Table 3 presents the means, standard deviations, and range for overall process quality and space available per child, teachers' age, and teachers' salary per month. On average, the participating toddler child care classrooms were of a quality that Harms and her colleagues (Harms et al., 1990a) consider inadequate. Data variability was low, revealing relatively homogeneous quality. Eighty percent of classrooms showed inadequate quality (i.e., with an overall score under 3) and only $20 \%$ of classrooms showed minimal quality (i.e., with an overall score between 3 and 5). Within the participating classrooms there were no high-quality classrooms with developmentally appropriate practices (i.e. with an overall score equal or superior to 5). The range of space available per child reflects considerable variations in classroom area and in number of children in the classroom. Portuguese legislation requires $2 \mathrm{~m}^{2}$ per child for young toddler classrooms and $2.5 \mathrm{~m}^{2}$ for older toddlers classrooms (Rocha, Couceiro, \& Madeira, 1996). Mean space available per child in both age groups is higher than stipulated, however, four classrooms for young toddlers (27\%) and nine classrooms for older toddlers $(60 \%)$ did not meet the requirements for physical space per child. The mean teachers' salary per month was relatively low (600 Euros are equivalent to 711 U.S. Dollars) and the range of teachers' salary reflected different professional status of untrained and trained teachers.

Hierarchical regression was employed to determine if space available per child and teachers' age and salary per month predicted overall classroom quality as measured by ITERS composite score. The hierarchical regression model that was used to predict overall process quality included three groups of variables. Block selection order was based on a structural stability criterion, that is, we first entered conditions we believed to be more stable or difficult to change, continuing with conditions more susceptible to be modified. Block 1 included one classroom structural variable. Block 2 included one variable related to teachers' characteristics. Block 3 included one variable related to teachers' working conditions. Regression assumptions on normality and absence of multicollinearity and outliers were checked and verified. No cases had missing data, $N=30$. Results of these analyses are displayed in Table 4.

After Bock 1 was entered, with space available per child in the equation, $R^{2}$ was not statistically different from zero. Space available per child alone did not predict overall process quality. The effect size computed for this structure variable was small. Block 2 significantly contributed to the overall process quality measured by ITERS. Addition of

Table 4

Summary of hierarchical regression analysis for variables predicting overall process quality $(N=30)$

\begin{tabular}{lccc}
\hline Variable & $B$ & S.E. $B$ & $\beta$ \\
\hline $\begin{array}{l}\text { Block 1 }\left(R^{2}=.062\right) \\
\quad \text { Space available per child }\end{array}$ & .081 & .060 & .249 \\
Block 2 $\left(\Delta R^{2}=.230^{* *}\right)$ & & & .07 \\
$\quad$ Space available per child & .121 & .055 & $.370^{*}$ \\
$\quad$ Teachers' age & -.033 & .011 & $-.495^{* *}$ \\
Block 3 $\left(\Delta R^{2}=.241^{* *}\right)$ & & & .33 \\
$\quad$ Space available per child & .145 & .046 & $.444^{* *}$ \\
Teachers' age & -.036 & .009 & $-.536^{* *}$ \\
$\quad$ Teachers' salary per month & .000 & .000 & $.497^{* *}$ \\
\hline
\end{tabular}

\footnotetext{
${ }^{*} p<.05$.
}

*** $p<.01$. 
teachers' age resulted in a statistically significant increment in $R^{2}$. With space available per child and teachers' age in the equation, a moderate effect on global quality was found. Block 3 also made a statistically significant contribution to overall process quality. Teachers' salary per month was a statistically significant predictor of overall process quality and its practical significance may be considered noteworthy. Overall process quality was statistically significantly related to the teacher characteristics included in the model. Teachers' age made the strongest unique contribution, although teachers' salary per month also made a statistically significant contribution. Higher process quality was associated with less age and higher salaries.

\section{Discussion}

Toddlers in the Metropolitan Area of Porto attend child care classrooms that, on average, do not have the basic health and safety requirements and do not provide the necessary materials to answer children' developmental needs (for example, there are insufficient pretend play materials with few themes available; pictures and mobiles are insufficient, and usually displayed at adult eye level; few soft toys, etc.). In these classrooms, the care provided is inadequate and the quality of environment is poor. For example, scores on items related to safety and health are particularly low namely because of handwashing practices and absence of emergency procedures. Only $20 \%$ of the observed classrooms revealed minimal quality, that is, met custodial care needs and, to some small degree, basic developmental needs. We did not observe good quality classrooms that appropriately answered the developmental needs of children or that provided personalized care. Mean results indicate absence of positive interaction, planning, personalized care as well as good materials. Reasons for this lack of developmental appropriateness may be due to a custodial conceptualization of infant and toddler care, opposed to an educational focus of preschool child care. Informal conversations with infant-toddler child care teachers led us to believe that infants and toddlers are generally viewed by early education professionals as being too young to respond appropriately to teaching activities. Another possible reason for the lack of developmental appropriateness of toddler child care classrooms may be the lack of teacher-specific training on education and care of children under 3 years of age. Portuguese teachers' initial training focuses almost exclusively on education and care for preschool children.

These results highlight the current concerns about the quality of care provided to younger children. In fact, although the potential positive effects of high-quality programs are well documented, several large-scale evaluations of childhood services, namely in the United States of America, revealed that high-quality classrooms are not the rule (e.g., Howes, Phillips, \& Whitebook, 1992). For example, the Cost, Quality and Outcomes Study (1995) showed that in the United States of America, only $8 \%$ of infant classrooms revealed high quality, susceptible of promoting the health and social and cognitive development of children. More troubling was the high percentage of classrooms with minimal or inadequate quality. About $40 \%$ of children attended infant and toddler classrooms of poor quality, considered to be eventually dangerous to their health and safety and harmful to their cognitive and social development.

These results should be carefully considered because of limited sample size and data collection procedures. Let us remember that ITERS' ratings, in our sample, are based on information gathered during an average 4-week observation period. Although this procedure provides more stable information on children' daily experiences in toddler child care it makes it difficult to compare our results with those of other studies whose quality ratings are based on small periods of observation. We must acknowledge the possibility that this extended period of observation may have lowered or increased our quality ratings because of more opportunities to witness less adequate aspects of child care functioning on one hand and more opportunities to observe additional instances of better quality practices on the other. Having used a widely accepted but unpublished translation of ITERS, we must also acknowledge the possibility of translation related bias.

The prediction of process quality from structural measures revealed that process quality was higher in classrooms with younger and better paid teachers. In fact, both teachers' age and salary per month were moderately associated with process quality. Results on teachers' age are somewhat contrary to our expectations as well as to some other studies in the same domain, in which older teachers were associated with better quality of care (e.g., van Ijzendoorn et al., 1998). One possible explanation is that working in toddler child care classrooms is exhausting and does not provide many career opportunities. Salaries are quite modest, and most caregivers do not have any chance to be promoted to higher-level jobs within or outside the organization, which means that there are no external incentives to providing good quality services. Younger caregivers may cope better with the unfavorable working conditions and restricted career 
perspectives than older caregivers. On the other hand, younger teachers, with more recent and up-to-date training may be better prepared for their practice. Another possible explanation for these results can be related to the lack of supervision, quality control, and in-service training that characterize Portuguese child care centers. Further research is necessary to document the mechanisms of the associations between quality of care and formal characteristics of caregivers.

Teachers' salary proved to be an indicator of process quality, as measured by the ITERS. This finding has emerged in other studies using similar methodology (e.g., Phillipsen et al., 1997). This result is relevant because salary is a variable that can be directly targeted for intervention or regulation. Specially useful to the discussion of the current results is the fact that Portuguese teachers working in infant and toddler classrooms have reduced pay levels and conditions of work, when compared to preschool teachers (particularly those working in the public sector) (OECD, 2001). This fact seems to mirror the widespread (but not investigated) belief that infant and toddler child care teachers are underappreciated at the government and societal level. Although the relationship of teachers' salary per month to actual quality of care is at best complex and indirect, it is a possibly useful indicator of center quality (e.g., Scarr, Eisenberg, \& Deater-Deckard, 1994).

Another well-known quality indicator, space available per child, was less correlated with process quality. Although only a small effect was found for space available per child, when combined with teachers' characteristics, this result has practical implications because it can be addressed by early education policies on child care.

In conclusion, our results indicate that overall quality must be improved in Portuguese toddler classrooms and that structural regulatable aspects such as teachers' salary and training, and space available per child can be key factors in this process. These results are compatible with OECD findings and policy recommendations on Portuguese early childhood education and care (OECD, 2001). In fact, the OECD review identified several issues for policy attention, namely the need for more attention to children from 0 to 3 years of age and to the educational quality of early childhood services, emphasizing the need to improve the training of staff and more systematic and effective self-evaluation procedures for settings and staff. To this effect, OECD has recommended incentives for staff working with infants and toddlers in order to raise their level of training to that of preschool teachers and to increase access to in-service training.

\section{Acknowledgements}

This study is part of a research project titled The quality of child interactions in family and day care settings and its influence on children's socio-cognitive development developed by the Department of Psychology of the University of Porto and was supported by grants from the Foundation of Science and Technology (POCTI/PSI/35207/2000). The second author was supported by a Doctoral Fellowship from the Fundação para a Ciência e a Tecnologia (BD/8317/2002). Cecília Aguiar is now at UIPCDE, ISPA.

The authors thank the teachers and directors of the centers that participated in the project along with the research team members, Ana Isabel Pinto, Ana Susana Almeida, Leen Poppe, Maria da Paz Mascarenhas, Pedro Lopes dos Santos, Orlanda Cruz and Sílvia Barros. The valuable comments and support of Margaret Burchinal and R.A. McWilliam are also appreciated.

\section{References}

Abbott-Shim, M., \& Sibley, A. (1987). Assessment profile for early childhood programs: Pre-school, infant, and school age. Atlanta, GA: Quality Assist.

Aguiar, C., Bairrão, J., \& Barros, S. (2002). Contributos para o estudo da qualidade em contexto de creche na área metropolitana do Porto [Contributions from the study of toddler child care in the metropolitan area of Porto]. Infância e Educação: Investigação e Práticas, 5, 7-28.

Bairrão, J., Barbosa, M., Borges, I., Cruz, O., \& Macedo-Pinto, I. (1990). Perfil nacional dos cuidados prestados às crianças com idade inferior a seis anos [National profile of services for children unde six years of age]. Lisboa, Portugal: Fundação Calouste Gulbenkian.

Bairrão, J., Leal, T., Abreu-Lima, I., \& Morgado, R. (1997). Educação pré-escolar [Preschool education]. In Ministério da Educação (Ed.), Estudos temáticos. Vol. II: A evolução do sistema educativo e o PRODE (pp. P17-P110). Lisboa, Portugal: Departamento de Avaliação, Prospectiva e Planeamento.

Bairrão, J., Leal, T., \& Gamelas, A. M. (1999). Educação pré-escolar em Portugal-Estudo de qualidade [Preschool education in Portugal-Quality study] Faculdade de Psicologia e de Ciências da Educação. Portugal: Universidade do Porto.

Bairrão, J., \& Tietze, W. (1995). A educação pré-escolar na União Europeia [Preschool education in the European Union]. Lisboa, Portugal: Instituto de Inovação Educacional.

Blau, D. M. (2000). The production of quality in child-care centers: Another look. Applied Developmental Science, 4(3), $136-148$. 
Cohen, J. (1992). Quantitative methods in psychology: A power primer. Psychological Bulletin, 112, 155-159.

Cost, Quality, Child Outcomes Study Team. (1995). Cost, quality, and child outcomes in child care centers public report (2nd ed.). Denver: Economics Department, University of Colorado at Denver.

Cryer, D., Tietze, W., Burchinal, M., Leal, T., \& Palacios, J. (1999). Predicting process quality from structural quality in preschool programs: A cross-country comparison. Early Childhood Research Quarterly, 14, 339-361.

European Child Care and Education (ECCE) Study Group. (1997a). European Child Care and Education: Cross national analyses of the quality and effects of early childhood programs on children's development. Final report submitted to European Union DG XII: Science, Research and Development. RTD Action: Targeted Socio-Economic Research.

European Child Care and Education (ECCE) Study Group. (1997b). Questionário de avaliação das características estruturais do jardim-de-infância $e$ da creche [Preschool and daycare structural characteristics questionnaire - Interview with the classroom teacher]. (Centro de Psicologia da Universidade do Porto. Linha de Investigação n 3: Psicologia do Desenvolvimento e Adaptação da Criança, FPCE-UP, Portugal).

Hagekull, B., \& Bohlin, G. (1995). Day care, family and child characteristics and socioemotional development. Early Childhood Research Quarterly, $10,505-526$.

Harms, T., \& Clifford, R. M. (1980). The Early Childhood Environment Rating Scale (ECERS). New York: Teachers College Press.

Harms, T., Clifford, R. M., \& Cryer, D. (1998). Early Childhood Environment Rating Scale-Revised. New York, NY: Teachers College Press.

Harms, T., Cryer, D., \& Clifford, R. M. (1990). Infant-Toddler Environment Rating Scale (ITERS) Frank Porter Graham Child Development Center. University of North Carolina at Chapel Hill.

Harms, T., Cryer, D., \& Clifford, R. M. (1990b). Infant-Toddler Environment Rating Scale (ITERS). [Escala de Avaliação do Ambiente de Creche]. Frank Porter Graham Child Development Center. University of North Carolina at Chapel Hill. [Portuguese translation available from the Faculdade de Psicologia e de Ciências da Educação da Universidade do Porto, Portugal].

Harms, T., Cryer, D., \& Clifford, R. M. (2003). Infant/Toddler Environment Rating Scale-Revised (ITERS-R). New York, NY: Teachers College Press.

Howes, C. (1997). Children's experiences in center based care as a function of teacher background and adult: Child ratio. Merrill Palmer Quarterly, $43,404-425$.

Howes, C., Phillips, D. A., \& Whitebook, M. (1992). Thresholds of quality: Implications for the social development of children in center-based child care. Child Development, 63, 449-460.

Instituto Nacional de Estatística. (2003). Resultados provisórios censos 2001 [2001 Census Temporary Results]. Retrieved December 15, 2003, from http://www.ine.pt

Katz, L. (1998). Cinco perspectivas sobre a qualidade [Five perspectives on quality]. In Ministério da Educação (Ed.), Qualidade e projecto na educação pré-escolar (pp. 15-40). Lisboa, Portugal: Ministério da Educação.

Lamb, M. (1998). Nonparental child care: Context, quality, correlates, and consequences. In I. E. Sigel \& K.A. Renninger, (Eds.) \& W. Damon (Series Ed.), Handbook of child psychology, Vol. IV: Child psychology in practice (5th ed., pp. 73-133). New York: John Wiley \& Sons, Inc.

Legendre, A. (2003). Environmental features influencing toddlers' bioemotional reactions in day care centers. Environment and Behavior, 35, 523-549.

Ministério da Educação. (2000). A Educação pré-escolar e os cuidados para a infância em Portugal [Early childhood education and care in Portugal]. Lisboa, Portugal: Departamento de Ensino Básico.

Ministério da Educação (2002). Ano escolar 2002/2003: Dados globais de referência [School year of 2002/2003: Global reference data]. Retrieved October 2002, from www.dapp.min-edu.pt/est_plan/pdf/mudar.pdf

National Institute on Child Health Human Development Early Child Care Research Network. (2005). Child care and child development: Results from the NICHD Study of Early Child Care and Youth Development. New York: The Guilford Press.

Organization for Economic Co-operation and Development. (2001). Early childhood education and care-Portugal: Background report. Paris, France: Organization for Economic Co-operation and Development. Available at http://www.oecd.org/document/49/0,2340,en_2649_ 34511_1941745_1_1_1_1,00.html

Organization for Economic Co-operation and Development. (2004). Babies and bosses: Reconciling work and family life. New Zealand, Portugal and Switzerland (Vol. 3). Paris, France: Organization for Economic Co-operation and Development. Available at http://www1.oecd.org/publications/e-book/8104161E.pdf

Phillipsen, L. C., Burchinal, M. R., Howes, C., \& Cryer, D. (1997). The prediction of process quality from structural features of child care. Early Childhood Research Quarterly, 12, 181-303.

Rocha, M. B. P., Couceiro, M. E., \& Madeira, M. I. R. (1996). Creche (Condições de implantação, localização, instalação e funcionamento). Guiões técnicos, $N^{\circ} .4$ [Infant-toddler child care (location, establishment and functioning conditions). Technical guidance, N. 4]. Lisboa, Portugal: Direcção-Geral da Acção Social, Núcleo de Documentação Técnica e Divulgação.

Scarr, S., Eisenberg, M., \& Deater-Deckard, K. (1994). Measurement of quality in child care centers. Early Childhood Research Quarterly, 9 , 131-151.

Tabachnick, B. G., \& Fidell, L. S. (1996). Using multivariate statistics (3rd ed.). New York: HarperCollins.

Tietze, W., Cryer, D., Bairrão, J., Palacios, J., \& Wetzel, G. (1996). Comparisons of observed process quality in early child care and education programs in five countries. Early Childhood Research Quarterly, 11, 447-475.

van Ijzendoorn, M. H., Tavecchio, L. C., Stams, G. M., Verhoeven, M. E., \& Reiling, E. J. (1998). Quality of center day care and attunement between parents and caregivers: Center day care in cross-national perspective. Journal of Genetic Psychology, 159, 437-454.

Vasconcelos, T., Orey, I., Homem, L. F., \& Cabral, M. (2002). Educação de infância em Portugal: Situação e contextos numa perspectiva de promoção de equidade e combate à exclusão [Childhood education in Portugal: Current state and contexts in a equity promotion and exclusion prevention perspective]. Lisboa, Portugal: Conselho Nacional de Educação.

World Health Organization. (1990). WHO Child Care Facility Schedule with user's manual. Division of Mental Health, Geneva, Switzerland: WHO. 